\title{
Uma discussão do papel da tecnologia na práxis
}

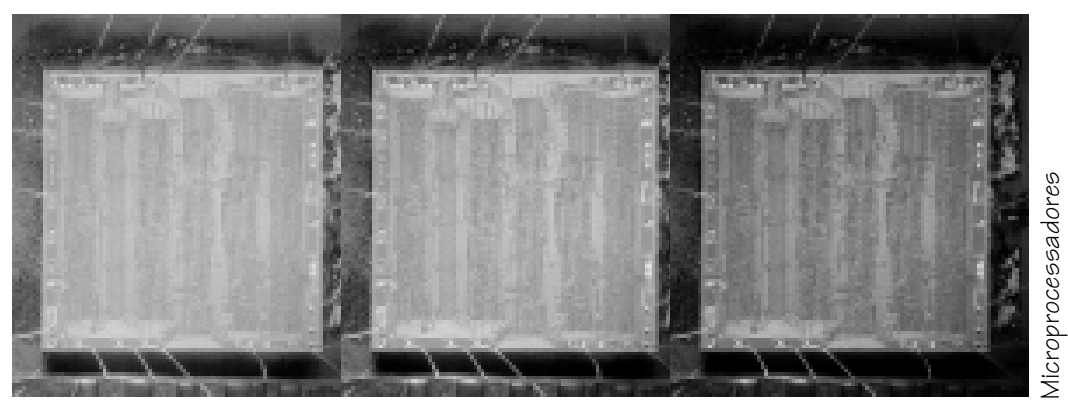

Alfredo Pereira Junior ${ }^{1}$

PEREIRA JR., A. A discussion of the role of technology in praxis, Interface _ Comunicação, Saúde, Educação, v.4 , n.6, 2000.

This paper discusses some of the aspects of the relation between praxis (human activity as a whole, dynamic and emancipative) and technology. The topics covered include: What does technology consist of? Is it intrinsically antagonistic to said praxis? How do dominant sociopolitical groups in contemporary society make use of technological development? How does this development affect those countries that are only scantily endowed with technology? The proposed conclusion is that, although technological progress has been used to expand social inequality and alienation in neo-capitalist society, technological know-how is nevertheless essential for consistent praxis.

KEY WORDS: tecnology; praxis; alienation.

Esse estudo discute alguns aspectos da relação entre "práxis" (atividade humana integral, transformadora e emancipatória) e a tecnologia. Alguns tópicos abordados são: Em que consiste a tecnologia? Seria ela intrinsecamente antagonista desta "práxis"? Como o desenvolvimento tecnológico é utilizado pelos grupos sóciopolíticos dominantes na sociedade contemporânea? Como esse desenvolvimento afeta os países pobres em tecnologia? A conclusão proposta é que, embora o progresso tecnológico seja utilizado na sociedade neocapitalista como meio de reprodução da desigualdade social e da alienação, o domínio da tecnologia também seria essencial para uma "práxis" consistente.

PALAVRAS-CHAVE: tecnologia; práxis; alienação.

\footnotetext{
${ }^{1}$ Professor do Departamento de Educação do Instituto de Biociências de Botucatu, Universidade Estadual Paulista, Unesp, São Paulo. E-mail: apj@ibb.unesp.br
} 
Nesse texto discuto três assuntos inter-relacionados: primeiro, como a questão tecnológica se relacionaria com o conceito marxiano da "práxis"; segundo, a possibilidade de que o progresso tecnológico contribua para a superação da alienação humana, $e$, terceiro, as restrições à tal superação na sociedade neocapitalista.

A antropologia filosófica moderna, de inspiração cartesiana, baseou-se em uma separação entre vida mental e corporal. Uma das tentativas contemporâneas de superar esse dualismo foi a antropologia marxiana, proponente do conceito de "práxis", expressando uma interação entre atividade teórica e prática, com vistas à transformação de uma realidade sócio-econômica injusta e alienante. Uma das variantes do conceito de "práxis", inspirada nos métodos políticos dos revolucionários russos (Lênine, Trotsky), propõe a associação entre "trabalhadores manuais" (proletários) e "trabalhadores intelectuais" (teóricos ativistas) em um mesmo partido político. Tal concepção ganhou nova conotação com o desenvolvimento tecnológico, que contribuiu para a formação de uma categoria de trabalhadores intelectuais assalariados, em posição social mais próxima a dos trabalhadores manuais que os teóricos ativistas do início do século. Nesse contexto, a questão da validade do progresso tecnológico se coloca de forma mais aguda. Seria a tecnologia intrinsecamente alienante, como foi proposto por diversos filósofos, ou seria potencialmente libertadora, para aqueles diretamente envolvidos no universo do trabalho produtivo?

Para as correntes filosóficas como a "Escola de Frankfurt", que concebem a "práxis" de forma idealizada (i.é., como proposta estética desvinculada de ações concretas de transformação da realidade física e social), o progresso tecnológico tem aparecido como fator de alienação humana. Concebendo a relação homem-natureza nos moldes do romantismo alemão ou da doutrina heideggeriana do "esquecimento do ser", tais correntes consideram a tecnologia intrinsecamente alienante, ao interpor entre o sujeito e o objeto o instrumento técnico, o qual, inevitavelmente, terminaria por desvirtuar as finalidades "autênticas" do sujeito e, conseqüentemente, transformaria os meios em falsos fins. É curioso verificar que tal concepção simplista já havia sido consistentemente criticada por Hegel na Ciência da Lógica, quando mostrou que a dialética de meios e fins não é necessariamente alienente para o sujeito, mas conduz a processos criativos nos quais o resultado final supera não só suas intenções originais como também as limitações dos instrumentos. Talvez esse argumento não tenha sido bem compreendido pelo jovem Marx, mas com certeza foi assimilado pelo Marx "maduro", que identificou as raízes da alienação nas relações de exploração (teoria da "mais-valia") e não na resistência dos instrumentos técnicos frente às intenções do sujeito.

Uma outra vertente de crítica incondicional da tecnologia provém de alguns grupos ligados ao movimento ecológico, que consideram que a destruição do ambiente seria conseqüência necessária de toda modalidade de progresso tecnológico. Essa vertente é contestada por outros grupos dentro do próprio movimento ecológico, que propõem a geração de tecnologias alternativas como meio de se readequar os processos de transformação, minimizando os danos ao ambiente.

Uma crítica da tecnologia que desconheça a necessidade de métodos 
produtivos eficazes e eficientes, para manter e aperfeiçoar uma sociedade que passou por um processo de explosão demográfica, tende para uma visão utopista e/ou exclusivista (i.é., no sentido de se defender um projeto acessível apenas para uma minoria). Ora, o progresso tecnológico consiste basicamente na transformação dos instrumentos de trabalho. Mais precisamente, a tecnologia é a união da ciência e da técnica, propiciando novos processos de transformação material e de uso da informação, que venham satisfazer necessidades e desejos dos consumidores.

Na sociedade atual - por muitos classificada como "sociedade tecnológica", dada a influência direta ou indireta da tecnologia nos diversos domínios da vida humana - existem mecanismos de propaganda que influenciam os consumidores no sentido de pagar pela satisfação trazida pelos avanços tecnológicos. Assim, por exemplo, televisores sem controle remoto, discos de vinil e carros com carburação são preteridos em prol de seus sucessores tecnológicos, mesmo que a diferença de funcionalidade não seja diretamente proporcional à diferença de preços. Na perspectiva aqui proposta, a reprodução da alienação estaria vinculada não à própria tecnologia, mas sim a ações de grupos econômicos interessados em obter lucro por meio da inovação tecnológica. Pelos métodos de convencimento como a propaganda em massa, o consumidor é induzido a gastar seus recursos de forma que não condiz com seus reais interesses. Porém, tal artifício não é consequência direta ou indireta da inovação tecnológica, pois a propaganda é igualmente utilizada para aumentar a venda de produtos tecnologicamente antiquados (às vezes, a prova do tempo é até mencionada como fator positivo para a escolha do produto).

A partir de seu papel chave nas esferas da produção e do consumo, o componente tecnológico tornou-se elemento diferencial nas transações comerciais. Na composição do capital e, conseqüentemente, na estrutura do preço das mercadorias, o incremento tecnológico aparece em progressivo destaque, em detrimento de outros fatores de custo, matéria-prima e mãode-obra. Tal mudança vem indubitavelmente afetar, de modo negativo, a balança comercial dos países pobres em tecnologia, mesmo que sejam ricos em recursos naturais e força de trabalho. Por exemplo, nos desdobramentos do "Plano Real" brasileiro, que inicialmente se baseou em uma equiparação entre moeda brasileira (o real) e o dólar, o peso da tecnologia nas transações comerciais entre os países pobres e ricos veio a se revelar. Após protelar a desvalorização do real como forma de manter os aparentes benefícios do plano para a massa da população, o governo terminou forçado a realizá-la, o que não foi suficiente para reequilibrar a balança, uma vez que nossos produtos, tecnologicamente desqualificados, tendem a baixar de preço no mercado internacional, ao passo que os produtos que importamos tendem a subir.

Tal situação nos leva a identificar o papel central da tecnologia na sociedade contemporânea, as oportunidades que se abrem e que se fecham a partir de sua hegemonia, $e$ os conflitos e limitações intrínsecos a esse padrão sóciohistórico. A principal diferença entre a sociedade atual - que podemos chamar de "neocapitalista"- e os mecanismos clássicos do capitalismo descritos no século passado por Marx

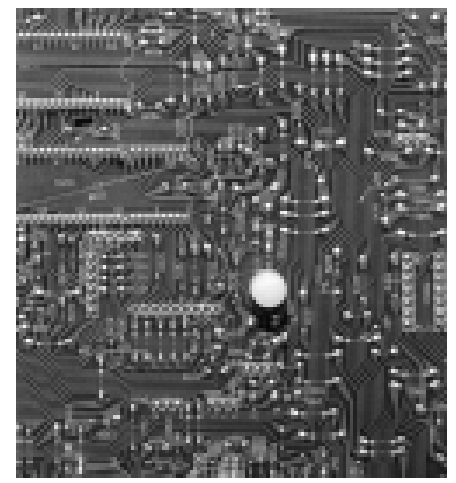




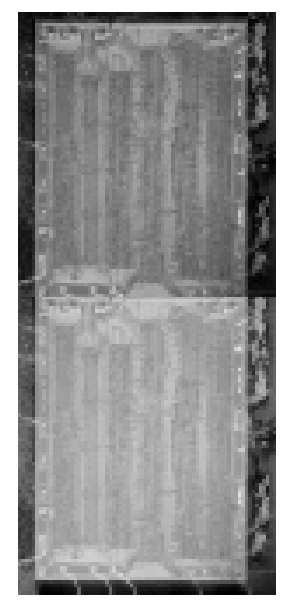

residiria em um "feedback" entre processos da infra e superestrutura sociais. A atividade científica se localiza na superestrutura, porém pela aplicação do conhecimento científico aos processos de produção, por meio da tecnologia, engendra-se uma dependência da infraestrutura frente à superestrutura. O fenômeno que nos países ricos poderia ser chamado de "círculo virtuoso da produção econômica e da inovação tecnológica" - isto é, o fato de que um PIB elevado favorece o investimento em pesquisa tecnológica, e esse investimento favorece o aumento do PIB - nos países pobres se torna um "círculo vicioso" - um baixo PIB impede investimentos ousados em pesquisa tecnológica, e a falta de tecnologia apropriada impede o crescimento do PIB.

Seria a dependência da infraestrutura frente à superestrutura restrita à esfera da ciência e da tecnologia? A resposta parece ser negativa, uma vez que essas mesmas atividades requerem uma série de experiências de vida, como condição para que o indivíduo ou grupo se capacite para exercê-las plenamente. Por exemplo, para se inserir competitivamente no mundo da computação, é necessário que o indivíduo ou grupo tenha uma experiência pessoal continuada com computadores. Evidentemente, apenas os membros de classes sociais relativamente abastadas podem ter acesso a essas experiências. O mesmo raciocínio se aplica aos países como um todo: para que o Brasil tivesse, por exemplo, pleno domínio da tecnologia nuclear, seria preciso que gerações de físicos pertencentes à nossa comunidade científica se dedicassem a desenvolver essa linha de pesquisa. A aquisição dos produtos tecnológicos pode ocorrer de forma rápida, mas a aquisição da própria tecnologia requer uma atividade continuada que muitas vezes não é acessível aos grupos de pesquisa dos países pobres.

Embora constitua condição necessária para o domínio da tecnologia, a existência de uma experiência prévia condizente não seria suficiente. Há um segundo requisito freqüentemente esquecido: a passagem de consumidor a produtor de tecnologia, que implica uma mentalidade empreendedora $e$ criativa. O progresso tecnológico tem aprofundado a distância entre uso da tecnologia pelo consumidor e domínio da tecnologia em si: os produtos são cada vez mais fáceis de serem manipulados pelo consumidor, enquanto os processos de produção tornam-se cada vez mais sofisticados $e$ incompreensíveis para o não-especialista ${ }^{2}$. Assistir TV não gera conhecimento de eletrônica, assim como usar um computador não gera conhecimento de programação. Para se utilizar a experiência adquirida como consumidor com vistas a se tornar produtor, não basta a assimilação dos processos já existentes (quando estes são divulgados) mas é também preciso desenvolver a capacidade de criar novos processos. Há uma dinâmica tecnológica que requer, mais que o simples acompanhar das tendências mercadológicas, o antecipar no vislumbre de novas alternativas, para se gerar empreendimentos que permitam o aproveitamento de oportunidades.

O problema da alienação na sociedade contemporânea estaria, na perspectiva aqui adotada, ligado ao fato de que numerosos contingentes da população se colocam nas relações sociais apenas ou majoritariamente como executores de tarefas e consumidores, e não como elaboradores. $\mathrm{O}$ processo de desalienação, portanto, se identificaria com a passagem de mero executor/consumidor para elaborador, ou seja, com um processo de
${ }^{2}$ Esse ponto me foi sugerido pelo prof. Luis A. Chinali em seminário sobre tecnologia. 
emancipação no qual os indivíduos e grupos adquirem autonomia sobre a produção de suas condições de vida. Tal processo necessariamente implica um maior domínio sobre as tecnologias utilizadas nos processos de produção e comunicação, pois sem tal domínio os sujeitos seriam incapazes de assumir o papel de elaboradores. Portanto, a tecnologia seria um componente necessário no processo de emancipação.

A velocidade da mudança tecnológica parece por vezes desafiar a capacidade da sociedade em absorver os novos produtos. Tal aparente contradição tem levado alguns analistas a postular a existência de limites para a sociedade tecnológica. Por exemplo, em um artigo intitulado "Tecnologia ainda não cria modelo econômico", o articulista Gilson Schwartz, do jornal Folha de São Paulo (5/9/99), referindo-se a uma pesquisa sobre estresse em professores universitários realizada pela Universidade da Califórnia (UCLA), concluiu que

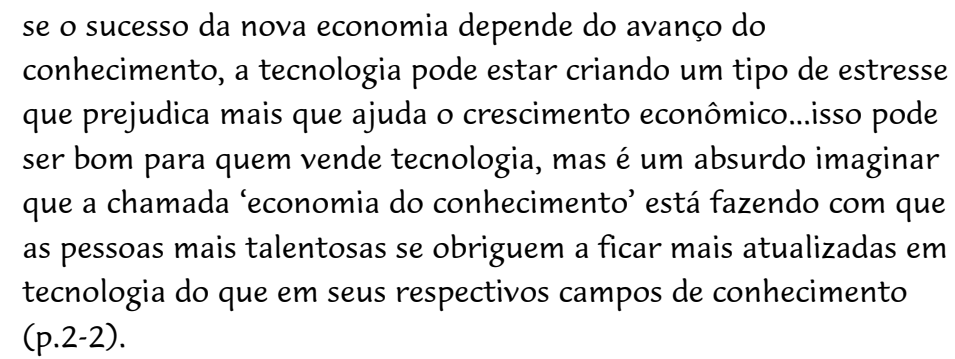

Tal conclusão me parece ser terrivelmente apressada, não levando em conta que o processo de desenvolvimento de novas tecnologias é profundamente desigual. A existência de um fosso entre a cultura já assimilada e as novas experiências acessíveis exclusivamente pelas novíssimas tecnologias constitui justamente a mola propulsora do marketing tecnológico. Essa mola propulsora, inicialmente baseada nos desejos individuais de acesso a tais experiências, cria um contexto de "pressão seletiva" (fazendo-se uma analogia com o evolucionismo darwiniano) em que a exclusão relativamente à novidade pode inviabilizar a progressão em áreas profissionais bem distintas daquela que gerou a inovação tecnológica. Portanto, o estresse diagnosticado pela pesquisa da UCLA faz parte do mecanismo pelo qual a sociedade tecnológica neocapitalista se reproduz, não constituindo uma contradição que inviabilizasse essa mesma sociedade. A ausência de funcionalidade da tecnologia para certos agentes sociais faz parte do

${ }^{3}$ Não seria uma contradição lógica - no sentido de se afirmar dois predicados incompatíveis entre si simultaneamente - mas uma contradição nas ações dos agentes sociais, ou seja, uma atividades imprescindível para a reprodução de seu status geraria conseqüências nocivas para os próprios agentes. mecanismo pelo qual se gera o lucro de outros agentes; para os agentes geradores das novíssimas tecnologias, não existe o problema de assimilá-la $e$, por esta razão, não ocorrem neles o referido estresse (se vier a existir, então teremos uma contradição no sentido sociológico do termo) ${ }^{3}$.

Ao se discutir o capítulo sobre as contradições da sociedade capitalista, verificamos que as contradições "clássicas" identificadas por Marx, geradoras das crises de superprodução e subemprego, são relativamente superadas pela sociedade tecnológica neocapitalista. Se os produtos que acionam o mercado tendem a se localizar na área da informação, os efeitos de uma

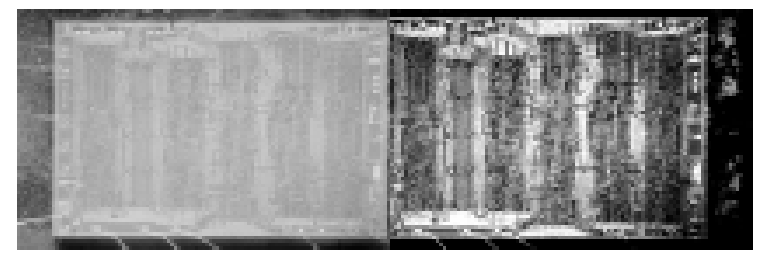

fevereiro, 2000 
superprodução se tornam menos visíveis ou mesmo transparentes. Por exemplo, nos casos de uma superprodução de café ou cebola, freqüentemente ocorrem cenas dramáticas de destruição dos bens pelos produtores, visando impedir a queda do preço; no caso de superprodução científica ou jornalística, os bens gerados em excesso (relativamente ao poder de compra dos assalariados) simplesmente não são consumidos $e$ desaparecem sem deixar rastro. Eventualmente algum cientista ou jornalista vem a se manifestar sobre o excesso de informação em circulação, mas os demais fingem que não ouviram e o sistema continua funcionando sem crises sérias. As reclamações sobre o excesso de informação caem na mesma vala comum das informações irrelevantes que passam desapercebidas; apenas as informações que atingem uma massa crítica de consumidores "sobrevivem".

Quanto à crise de subemprego, ao mesmo tempo em que a sofisticação tecnológica subtrai postos de trabalho manual - um processo ainda em curso nos países pobres, mas já ultrapassado em vários países ricos - ela contribui para gerar novas frentes de trabalho com custo operacional consideravelmente menor. Pensemos nas várias modalidades de trabalho que utilizam basicamente um computador de porte médio conectado a um sistema privado e/ou público de processamento e/ou comunicação. Além da redução do custo de geração de emprego, diversas novas áreas de atividade têm emergido, no bojo do processo pelo qual as relações sociais "diretas" (p.ex., na rua, praça pública, campo de futebol) são substituídas por relações mediatizadas por instrumentos tecnológicos (p.ex., via Internet, Shopping Centers, Sistemas de Saúde). Todas as relações mediatizadas pela tecnologia constituem fonte de lucro para os proprietários dos instrumentos (no caso da Internet, os fabricantes de computadores, provedores, criadores de software, bancos cujos cartões são utilizados para compras etc.; no caso dos Shopping Centers, proprietários de 'griffes', agências de planejamento, marketing e publicidade, redes de alimentação padronizada etc.; no caso dos Sistemas de Saúde, produtores e exploradores de equipamentos médicos, fabricantes e comerciantes de drogas farmacêuticas, administradores de convênios etc.). Conseqüentemente, em todas essas atividades surgem

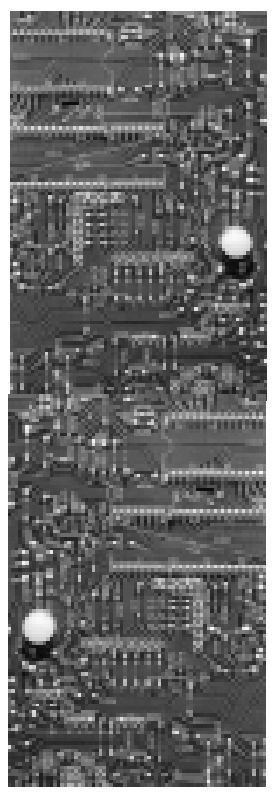
postos de emprego assalariado, necessários não só para implementar esses serviços como também para se extrair a "mais-valia" que é componente essencial do lucro. Nesse contexto, o problema do subemprego se reduz a dois subproblemas menos graves, não geradores de crises capazes de colocar em cheque o sistema neocapitalista: o problema do controle demográfico, que consiste em se reduzir a taxa de reprodução biológica, reduzindo, por conseqüência, os contingentes de desempregados estruturais; e o problema da melhoria do nível técnico e cultural da população, tornando-a apta a ocupar os novos postos de trabalho.

Uma vez convencidos da inexorabilidade do determinante tecnológico, nos restaria perguntar: quais as oportunidades que se apresentam para um país como o Brasil, no contexto da globalização deste padrão societário, e o que podemos fazer para melhor aproveitá-las? Observemos de início que a sociedade tecnológica não se opõe nem substitui a sociedade industrial que a precede 
historicamente; todo o processo de sofisticação tecnológica pressupõe a existência de uma estrutura industrial capaz de implantar as inovações dos processos de produção, e um mercado consumidor interessado nos novos produtos. Esse aspecto é freqüentemente esquecido pelos teóricos do "pósmoderno"; por exemplo, em uma interessante e famosa entrevista concedida ao programa Roda Viva, da TV Cultura brasileira, em 04/01/99, o sociólogo italiano Domenico de Masi

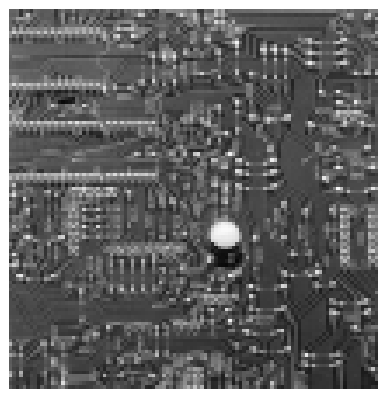
declarou que "um país pode passar diretamente para o pós-industrial, sem perder tempo na fase industrial, desde que tenha condições: grandes universidades, uma grande literatura e uma grande arte". Um análogo computacional de tal raciocínio seria a afirmação de que um excelente "software" dispensaria o "hardware"...

Como não podemos competir diretamente no domínio da pesquisa e do desenvolvimento científico/tecnológico, nos restaria competir na esfera das condições materiais de base que suportam a estrutura industrial que suporta a sociedade tecnológica. Dentre os diversos tipos de recursos básicos necessários para tal estrutura, três deles apresentam tendência à escassez, sendo que nosso país é afortunadamente rico em todos eles: a) recursos hídricos; b) recursos energéticos; c) outros recursos ambientais ligados à qualidade de vida, incluindo-se o lazer (turismo).

Para finalizar este estudo proponho uma breve reflexão sobre a questão energética, mais especificamente a respeito da utilização do álcool como combustível automotivo. Decorre da análise anterior que, para se inserir competitivamente na economia globalizada atual, não basta a um país possuir recursos materiais, é ainda mais importante que tenha uma tecnologia adequada para sua transformação e comercialização. Como na maioria dos processos de transformação as pesquisas tecnológicas foram feitas em outros países, torna-se mais econômico para as empresas aqui instaladas - sejam multinacionais ou não - copiar ou adquirir esses conhecimentos prontos, e adaptá-los para uso interno. No caso do álcool, tal pesquisa externa praticamente não existe, pois esse combustível requer condições específicas, como clima tropical e disponibilidade de vastas áreas agricultáveis, para ser produzido. Como é vastamente sabido, durante um par de décadas as agências públicas de pesquisa e financiamento desenvolveram um programa de inovação tecnológica e financiamento/ subsídio, o Pró-Álcool, para se criar uma alternativa brasileira ao combustível petrolífero. Contudo, uma relativa baixa do preço do petróleo, ao final dos anos oitenta, ligada ao aperfeiçoamento dos motores a gasolina, quase inviabilizou tal programa, fazendo com que no contexto atual, de revalorização do preço do petróleo, a maior parte da frota de veículos nacionais fosse ainda movida a gasolina.

Uma baixa estratégica do preço do produto, durante cerca de seis meses no ano de 1999, colocando o custo do álcool na proporção de um terço do custo da gasolina, permitiu ao programa recuperar parte de sua credibilidade. Contudo, após a venda dos estoques acumulados, um acordo entre o governo federal e os grandes usineiros elevou o preço a mais da metade do preço da gasolina. Nesse incidente podemos vislumbrar algumas das principais restrições ao usufruto democrático da tecnologia. É evidente 
que o fornecimento do álcool, assim como o gás natural, a baixo custo, certamente beneficiaria um amplo setor da população brasileira. Contudo, isso não seria viável para o governo federal e usineiros, por uma série de razões. Em primeiro lugar, é preciso reconhecer que a pesquisa realizada não teve como objeto o próprio álcool enquanto combustível; ou seja, não se desenvolveram novos processos para aumentar sua eficiência, permitindo inclusive sua utilização nos motores a gasolina. Ao contrário, a estratégia adotada foi a de modificar os motores originalmente planejados para funcionar a gasolina, para que funcionassem com o álcool. Tal estratégia implica na introdução de fatores de ineficiência e ineficácia, gerando contradições que tornam mais penosa a implantação do programa: necessidade de produção de dois tipos de equipamento; menor rendimento do álcool (apesar da maior octanagem); custos de distribuição; e geração de confusão na mente dos consumidores. Em segundo lugar, devido a razões políticas e acordos possivelmente ilegais, o governo federal tem sistematicamente financiado e favorecido grandes usineiros que não têm qualquer compromisso com a inovação tecnológica. Alguns pequenos usineiros, que desenvolveram métodos mais eficientes de produção do combustível, são capazes de fornecê-los a preços de atacado mais baixos, porém as grandes redes distribuidoras multinacionais, e a própria Petrobrás, têm sistematicamente proibido os postos de combustível que as representam de adquirir o álcool dos produtores independentes e repassá-lo a menor custo para o consumidor.

O exemplo acima ilustra a perspectiva delineada ao longo desse pequeno ensaio, ou seja, que o progresso tecnológico não seria intrinsecamente um instrumento de reprodução da exploração e alienação humanas, embora seja amplamente utilizado como ferramenta para a realização dos interesses dos setores dominantes na sociedade.

Em conclusão, após discutir a relação tecnologia-práxis no plano conceitual, e no contexto da sociedade neocapitalista contemporânea, sustento a visão de que a tecnologia é um componente necessário da práxis, $e$ que pode vir a beneficiar amplos contingentes da população, desde que o padrão de relações sócio-políticas vigente seja alterado, de modo a quebrar restrições que impedem a disseminação de seus benefícios para a maioria da população.

PEREIRA JR., A. Una discusión del papel de la tecnología en la praxis, Interface - Comunicação, Saúde, Educação, v.4 , n.6, 2000.

Este estudio discute algunos aspectos de la relación entre praxis (actividad humana integral, transformadora y emancipadora) y tecnología. Algunos de los tópicos planteados son: $i$ en qué consiste la tecnología? ¿Será intrínsecamente antagonista de esta praxis? ¿Cómo utilizan el desarrollo tecnológico los grupos socio-políticos dominantes en la sociedad contemporánea? ¿Cómo afecta este desarrollo a los países pobres en tecnología? La conclusión propuesta es que, aunque el progreso tecnológico se utilice en la sociedad neocapitalista como medio de repoducción de la desigualdad social y de la alienación, el dominio de la tecnología también sería essencial para una praxis consistente.

KEY WORDS: tecnología; praxis; alienación. 